\title{
Development of sensitive, specific, point of care enzyme-linked immunosorbent assay combined with DBS and hand-held ELISA reader for the rapid detection of hepatitis $C$ virus in resource-limited settings.
}

\author{
Soumendra Nath Maity ${ }^{1,2,3^{*}}$, Prudhvi Chand Mallepaddi ${ }^{2}$, Nagababu Pyadala ${ }^{1,2}$, Sujaya \\ Raghavendra ${ }^{4}$, Sai Sailesh Kumar ${ }^{5}$, Vijayaraghavan ${ }^{1}$, Rathnagiri Polavarapu ${ }^{2,6,7}$ \\ ${ }^{1}$ Department of Research, Saveetha University, Thandalam, Chennai, Tamil Nadu, India \\ ${ }^{2}$ Department of Clinical Research Laboratory, Genomix Molecular Diagnostics Pvt. Ltd, Kukatpally, Hyderabad, India \\ ${ }^{3}$ Department of Microbiology, Malla Reddy Institute of Medical Sciences, Hyderabad, India \\ ${ }^{4}$ Department of General Medicine, Mahatma Gandhi Medical College and Research Institute, Pondicherry, India \\ ${ }^{5}$ Department of Physiology, DM Wayanad Institute of Medical Sciences, Kerala, India \\ ${ }^{6}$ MNR Foundation for Research and Innovation, Sangareddy, Telanagana, India \\ ${ }^{7}$ Genomix CARL Pvt. Ltd, Pulivendula, Andhra Pradesh, India
}

\begin{abstract}
Background: Hepatitis $\mathrm{C}$ virus cause liver infection which can lead to liver cirrhosis and hepatocellular carcinoma. Identification of hepatitis $C$ virus infection initially depends on the antibody screening test. Aim and objectives: We developed highly specific and sensitive recombinant protein-based HCV ELISA and combined the assay with Dried Blood Spot (DBS) assay and hand-held ELISA reader to establish its use in limited resource areas as well as in field level.

Materials and methods: A total of $\mathbf{6 1 0}$ specimens were collected for assay validation purpose. To check the proficiency of our diagnostic strategy, we compared our test results with standard HCV chemiluminescence enzyme immune assay. The Institutional Ethical Committee approved this study (IEC). NCSS 11 statistical software analysed all the data. The correlation-regression was done to compare the assay. The level of significance of this study was $p<0.05$.

Results: Among 60 known reactive specimens, 59 showed reactive by HCV ELISA and chemiluminescence enzyme assay. Therefore sensitivity for both the assay recorded $98.33 \%$. Out of 150 known non-reactive samples, both the method showed the nonreactive result. Thus specificity calculated $100 \%$. While HCV ELISA tested with DBS, we found no significant difference in specificity and sensitivity of the assay $\left(r^{2}=0.9940\right)$. ELISA optical density value obtained by Hand-held ELISA reader showed better performance as compared to Tulip ELISA plate reader $\left(r^{2}=0.9921\right)$. While performed field study, out of 400 specimens, 6 showed reactive by both the methods. Therefore specificity and sensitivity was $100 \%$ for in-house HCV ELISA as compared to chemiluminescence assay. In this case, also we found a good performance of DBS assay $\left(r^{2}=0.9476\right)$. There was a good correlation between $O . D$. obtained by hand-held ELISA reader and Tulip ELISA plate reader $\left(\mathbf{r}^{2}=\mathbf{0 . 9 9 2 3}\right)$.

Conclusion: According to our study report, in-house HCV ELISA is highly specific and sensitive method. Addition of DBS assay and hand-held ELISA reader makes it possible to run the assay in limited resource settings as well as in field level or outside the standard laboratory setup. This unique HCV diagnostic strategy can reduce the global burden of HCV infection.
\end{abstract}

Keywords: Hepatitis C virus (HCV), Enzyme-linked immunosorbent assay (ELISA), Chemiluminescence enzyme immune assay, Dried blood spot (DBS), Hand-held ELISA reader. 


\section{Introduction}

Hepatitis $\mathrm{C}$ virus is the major causative agent of hepatitis and hepatocellular carcinoma worldwide. In the early 1980s among the individuals with post transfusion-associated hepatitis, $10 \%$ patients had Non A, Non B type hepatitis. Therefore the causative agent was designated as NANBH [1,2]. In spite of any standard virological method the causative agent named as enveloped RNA virus based on the study in chimpanzee animal model. In addition to that NANBH outbreaks were also found frequently in community with well-defined route of transmission [3-7]. The HCV infection is major global health problem with estimated 130-170 million individual infected worldwide and higher prevalence rate found in African countries [8-10]. Parenteral route is the most common way of transmission of HCV infection, followed by sharing of needle among drug abusers and during medical interventions. The blood and blood products transfusion is one of the significant risk factor for transmission of $\mathrm{HCV}$ infection. Mother to child transmission, sexual contact, and needle stick injuries are less frequently reported for $\mathrm{HCV}$ transmission. The $\mathrm{HCV}$ transmission rate is varies between developed and developing countries. In developed countries there is less chance to get $\mathrm{HCV}$ infection through blood and blood product transfusion but new infection may occur due to un-cleaned needle sharing [11-13]. In case of developing countries lack proper screening strategies and medical procedures increase the rate of transfusion-related HCV infection [14]. The typical asymptomatic clinical features and high rate of chronicity makes it most vulnerable pathogen causing hepatitis. The acute phase of the disease is clinically silent; therefore it is difficult to diagnose the case. Hence most of the patients develops chronic hepatitis and may identify in late stage of the disease. The severity of HCV infection is varies among individuals from few years to decades and cause liver cirrhosis and hepatocellular carcinoma. But recently the disease spectrum has changed due to implementation of systemic screening test $[15,16]$. Acute HCV infection asymptomatic for several years, so diagnosis can be done incidentally with other investigations or symptoms suggesting chronic liver inflammation [17]. Therefore HCV diagnosis is based on two groups, those indirectly detecting the virus and those detecting the virus directly. In indirect detection rely on serological findings of $\mathrm{HCV}$ specific antibodies in specimen. The indirect method detects the HCV RNA and HCV antigens [18-21]. The enzyme immune assays are the useful screening test for the detection of HCV specific antibodies. Recently third-generation immune enzyme assay is routinely used in diagnostic laboratories, which based on the detection of specific antibodies against $\mathrm{HCV}$ antigens, such as HCV core, NS3, NS4, and NS5. This method is widely used in diagnostic centres as well as in screening of large samples. Rapid immunochromatographic test kits are available at point of care diagnostic test for HCV infection. Although this method requires less time and easy to use in resource-limited settings, but due to low specificity and sensitivity as compared to ELISA, less useful for screening of blood and blood products as well as other specimens. The recombinant immune blot assay can be used as a confirmatory test for repeatedly ELISA reactive specimens. Other than these methods, nucleic acid amplification-based assays such as PCR, RT-PCR, LAMP-PCR, etc. are the gold standard methods for detection of virus-specific nucleic acid. But due to the costeffectiveness, the requirement of sophisticated instruments and trained personnel; PCR based assays are not routinely used in diagnostic laboratories. Although there are several diagnostic tests available for HCV detection, but till now burden of HCV related diseases are challenging worldwide. This is may be due to the lack of proper diagnostic strategies available in every part of the world. Mostly in poor nations, individuals from remote areas are usually deprived from standard diagnosis and management of infectious diseases [22-25]. Therefore infectious diseases are increasing rapidly all over the world. There is need of specific, sensitive, inexpensive, point of care diagnostic assays to detect $\mathrm{HCV}$ infection in resource-limited settings. Therefore in this study, we came up with highly specific and sensitive, inexpensive enzyme-linked immunosorbent assay combined with sample collection filter card and Genomix handheld ELISA reader for the detection of $\mathrm{HCV}$ infection in limited resource areas.

\section{Materials and Methods}

\section{Participants and ethical consideration}

This study was carried out in two different centres of Genomix Molecular Diagnostic Pvt. Ltd. and Malla Reddy Hospital, Hyderabad from October 2016 to June 2017. Two sets of the sample used for development of HCV ELISA kit. First set was 60 known reactive and 150 non-reactive specimens. Another 400 unknown specimens collected from Malla Reddy hospital for the kit validation process. This study approved by Institutional Ethical Committee (IEC) of MNR Medical College and Hospital, Sangareddy, Telangana, conducted on 11-08-2016; approval number ECR/834/Inst/TG/2016. The proper consent form filled by all the participants included in the study.

\section{Inclusion and exclusion criteria}

All age group and gender included in this study. Patients were not willing to give his/her consent excluded from the study group.

\section{Genomix hand-held ELISA reader}

The hand-held ELISA reader is easy to use and mobile, only $400 \mathrm{~g}$ in weight. This reader is easy to carry from one place to another place with facilities like; exchangeable filters, battery operated and smartphone usage for ELISA data sharing (Figure $1)$.

\section{Development and validation of HCV enzyme-linked immunosorbent assay}

Hepatitis $\mathrm{C}$ virus recombinant proteins such as Core protein, NS3, NS4, and NS5 obtained from Genomix Biotech Inc., USA. The proteins diluted in sodium carbonate and 
Development of sensitive, specific, point of care enzyme-linked immunosorbent assay combined with DBS and handheld ELISA reader for the rapid detection of hepatitis $C$ virus in resource-limited settings

bicarbonate coating buffer with a concentration of $25 \mathrm{ng} / \mathrm{well}$. $100 \mu \mathrm{l}$ of protein mixture placed on the F8-maxiSorp immunomodule microtitre wells and incubated overnight at $4^{\circ} \mathrm{C}$ temperature. After overnight incubation microtitre wells were washed five times with $300 \mu \mathrm{l} /$ well of wash buffer (phosphate buffered saline-tween 20). Then microtitre wells were blocked with $2 \%$ casein and incubated 1 hour at $37^{\circ} \mathrm{C}$ temperature. After incubation period washed the wells by using wash buffer. Afterwards, HCV antigen coated microtitre wells were placed overnight under humidifier. $\mathrm{HCV}$ recombinant protein coated microtitre wells were packed in an aluminium foil with silica gel for the further testing purpose.

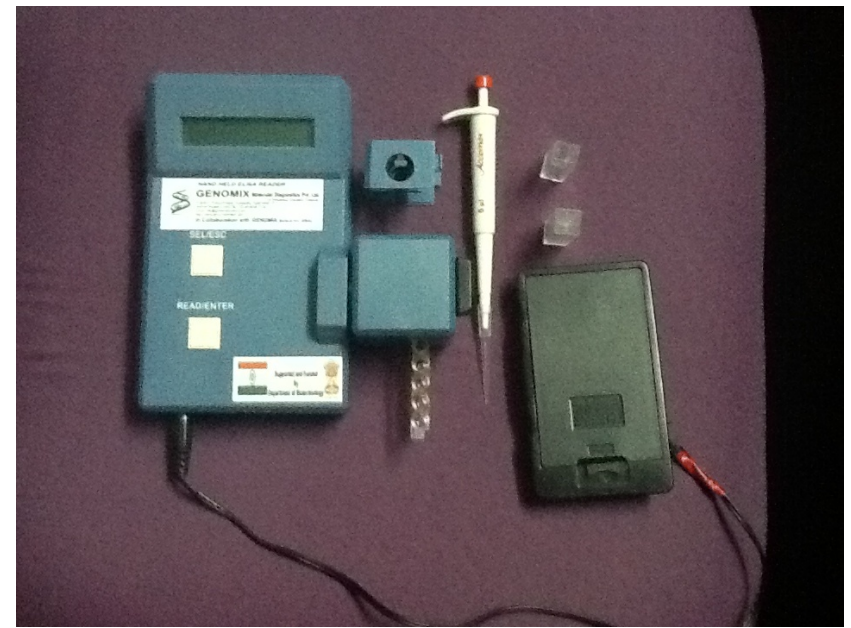

Figure 1. Genomix Hand-held ELISA reader in point of care diagnostics.

\section{Evaluation of in-house HCV ELISA by using known specimens}

The specimens tested by HCV real-time PCR (Qiagen, USA) were used in the HCV ELISA kit validation process. To check the sample stability in filter paper-based sample collection, placed one drop of each specimen into the sample collection filter card (Genomix Biotech Inc. USA) and stored at room temperature. Another part of direct serum specimens used for HCV ELISA. The dried blood spot filter paper was cut into small pieces and soaked it in sample diluents, gently vortex it, and the supernatant collected for further ELISA procedure. Two sets of specimens run in HCV ELISA separately. In the case of direct serum specimens, ten $\mu$ l of serum placed on the $\mathrm{HCV}$ antigen coated microtitre well with the addition of $100 \mu \mathrm{l}$ of sample diluents. $100 \mu \mathrm{l}$ specimen collected from filter paper strip was placed directly on wells and one well-kept as blank. The wells were covered with paper strip and incubated for $1 \mathrm{~h}$ at $37^{\circ} \mathrm{C}$ temperature. After incubation period wash microtitre wells five times with wash buffer solution. After gently tapping the wells to remove extra wash buffer added $100 \mu \mathrm{l}$ of Antihuman IgG1 antibody into each well and incubated for another $1 \mathrm{~h}$ at $37^{\circ} \mathrm{C}$ temperature. The washing step was repeated five times with wash buffer. Then add $100 \mu$ of TMB substrate solution in each well and incubated for $15 \mathrm{~min}$ at room temperature in dark place for the development of color. After the incubation period or color, development adds $100 \mu \mathrm{l}$ of 0.5
$\mathrm{N} \mathrm{H}_{2} \mathrm{SO}_{4}$ stop solution in each well to stop the excess colour development. The optical density measured at $450 \mathrm{~nm}$ by using both ELISA plate reader (Tulip Diagnostics, India) and Handheld ELISA reader (Genomix Biotech Inc. USA).

\section{Evaluation of HCV ELISA in field level}

A total of 400 specimens were evaluated by using both sample collection filter card and Hand-held ELISA reader. In-house HCV ELISA test result compared with the standard Chemiluminescence enzyme immune assay (Ortho-Clinical Diagnostics, USA). The in-house HCV ELISA procedure followed the procedure as mentioned earlier.

\section{Statistical analysis}

All test results data were analysed by statistical software NCSS 11. Correlation-Regression was performed to compare the methods included in this study. The $\mathrm{p}<0.05$ is significant.

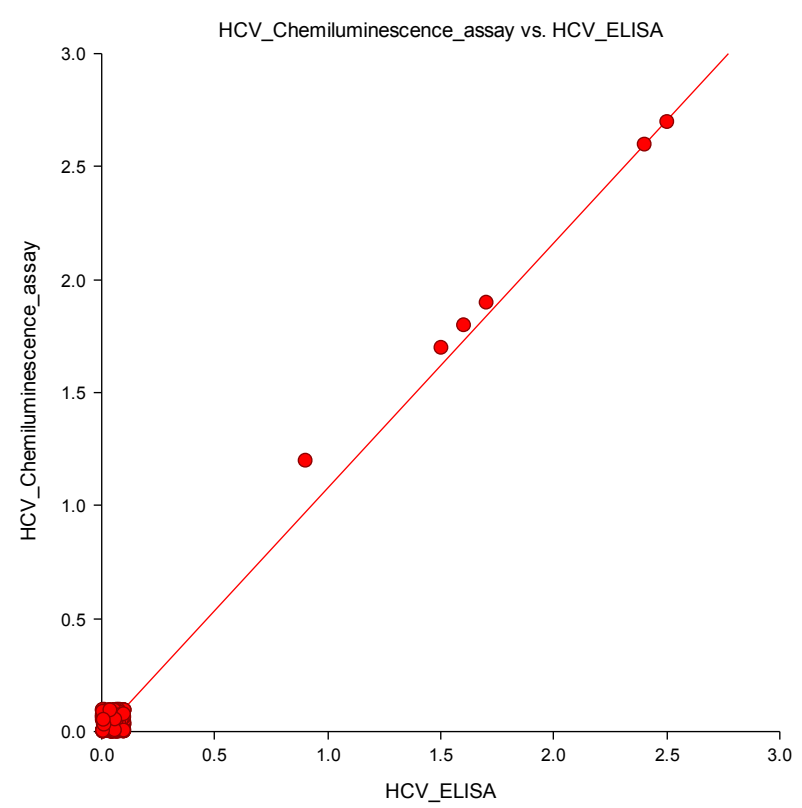

Figure 2. Comparison of ELISA and chemiluminescence assay for the diagnosis of $H C V .{ }^{*}$ The value of $R^{2}$ for HCV ELISA is 0.9559. The correlation between HCV Chemiluminescence assay and HCV ELISA is 0.9777. The significance level of this t-test is 0.0000. Since $0.0000<0.0500$, the hypothesis that the slope is zero is rejected.

\section{Results}

\section{Evaluation of HCV ELISA with known reactive and non-reactive specimens}

A total of $60 \mathrm{HCV}$ reactive specimens confirmed by $\mathrm{HCV}$ Real-time PCR, among them 59 samples showed reactive by in-house HCV ELISA, and one sample reported the false nonreactive result. Therefore our assay sensitivity was recorded 98.33\% as compared to HCV RT-PCR. While tested with HCV chemiluminescence method, 59 out of 60 specimens showed the reactive result. Thus the sensitivity of HCV chemiluminescence calculated as $98.33 \%$. Another way out of 
150 RT-PCR confirmed non-reactive samples were showed nonreactive result by our in-house HCV ELISA as well as for $\mathrm{HCV}$ chemiluminescence assay. Hence assay specificity for both methods was calculated $100 \%$ (Table 1 and Figure 2). There was no significant difference found in ELISA O.D. value obtained by using sample filter card and direct vacutainer specimen (Figure 3). Genomix Hand-held ELISA reader performed better as compared to existing ELISA plate reader (Tulip Diagnostics, India) (Figure 4).

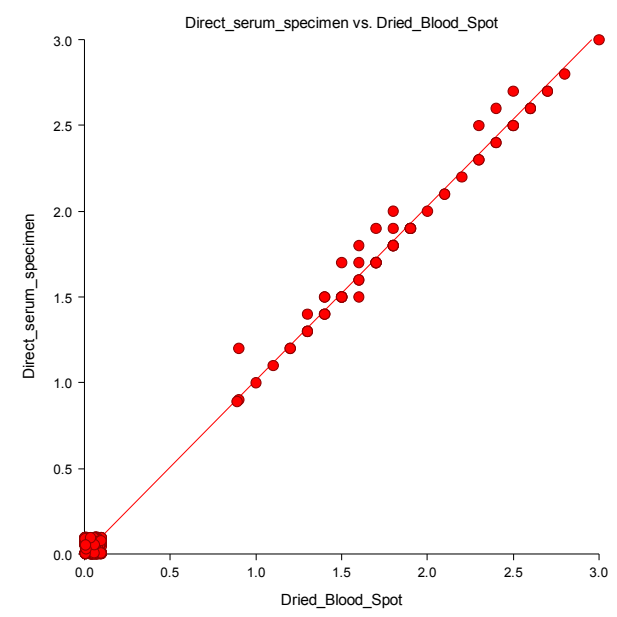

Figure 3. To check the suitability of Dried Blood Spot (DBS) in HCV diagnosis $(n=210) .{ }^{*}$ The $R^{2}$ value for dried blood spot is 0.9940 . The correlation between direct serum specimen and dried blood spot is 0.9970. The significance level of this t-test is 0.000 .

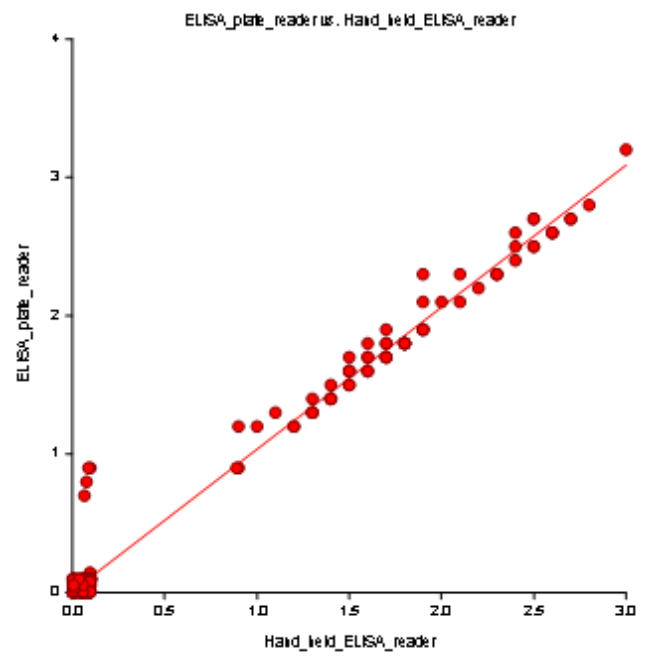

Figure 4. Comparison of Hand-held ELISA reader and Tulip ELISA plate reader $(n=210)$. ${ }^{*}$ The value of $R$-Squared, the proportion of the variation in ELISA plate reader that can be accounted for by variation in Hand held ELISA reader, is 0.9843. The correlation between ELISA plate reader and Hand held ELISA reader is 0.9921 . The significance level of this t-test is 0.0000 . Since $0.0000<0.0500$, the hypothesis that the slope is zero is rejected.

\section{Evaluation of HCV ELISA in field}

400 specimens were collected in both vacutainer and Genomix sample collection card, tested by in-house HCV ELISA method. Our test result compared with standard HCV chemiluminescence enzyme immune assay result. Out of 400 specimens, six specimens showed reactive for HCV by both the technique and 394 samples recorded as non-reactive for $\mathrm{HCV}$. Therefore the sensitivity and specificity were reported $100 \%$ for in-house HCV ELISA as compared to HCV Chemiluminescence method (Table 2). There was no difference in ELISA O.D. value obtained from vacutainer specimen, and dried blood spot specimen (Figure 5) and no significant difference found in O.D. value recorded from Genomix Handheld ELISA and existing ELISA plate reader (Figure 6).

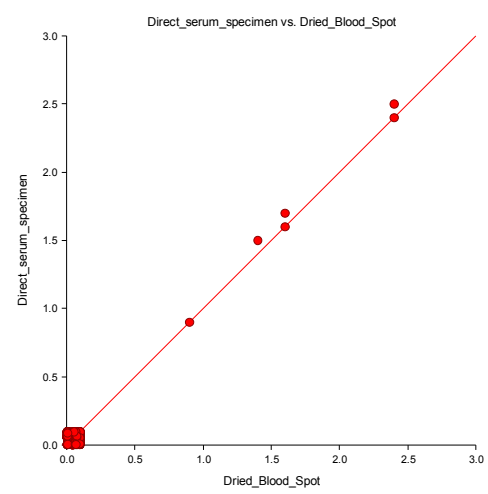

Figure 5. To check the suitability of Dried Blood Spot (DBS) in HCV diagnosis $(n=400)$. " The value of $R$-Squared, the proportion of the variation in direct serum specimen that can be accounted for by variation in dried blood spot, is 0.9476. The correlation between direct serum specimen and dried blood spot is 0.9735. The significance level of this t-test is 0.0000 . Since $0.0000<0.0500$, the hypothesis that the slope is zero is rejected.

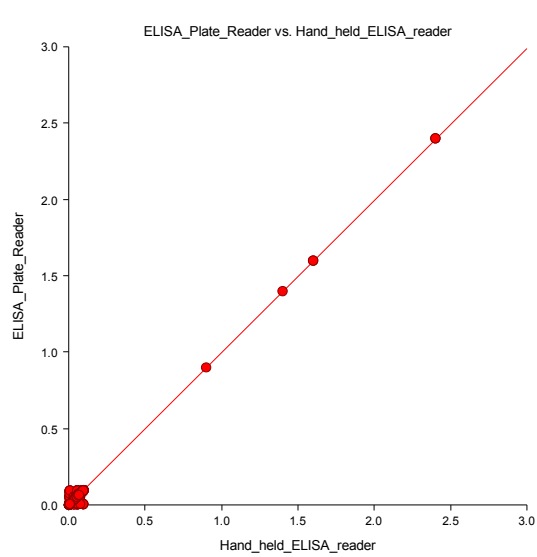

Figure 6. Comparison of Hand-held ELISA reader and Tulip ELISA plate reader $(n=400) .{ }^{*}$ The value of $R$-Squared, the proportion of the variation in ELISA Plate Reader that can be accounted for by variation in Hand held ELISA reader, is 0.9923. The correlation between ELISA Plate Reader and Hand held ELISA reader is 0.9961. A significance test that the slope is zero resulted in a t-value of 226.1950. The significance level of this t-test is 0.0000. Since $0.0000<0.0500$, the hypothesis that the slope is zero is rejected.

\section{Discussion}

Hepatitis $\mathrm{C}$ virus causes life-threatening liver infection, and until 1989 it was thought as non A non B type of hepatitis 
Development of sensitive, specific, point of care enzyme-linked immunosorbent assay combined with DBS and handheld ELISA reader for the rapid detection of hepatitis $C$ virus in resource-limited settings

which transmitted parenterally [26]. Hepatitis $C$ viral infection can cause acute and chronic hepatitis, including liver cirrhosis and hepatocellular carcinoma. The major causes of $\mathrm{HCV}$ infection are such as unscreened blood transfusion, use of unsterile needles and syringes [26-29]. Currently HCV 3rd generation enzyme immune assay reduces the risk of transmission of $\mathrm{HCV}$ infection through blood and blood product transfusion [23-30]. HCV enzyme immune assay use HCV-encoded recombinant proteins and the specificity and sensitivity reported $96 \%$ and $99 \%$ respectively. All the reactive $\mathrm{HCV}$ enzyme immune assay results are retested in duplicate and can confirm by Line Immunoassay (LIA), Recombinant Immune Blot Assay (RIBA) or nucleic acid amplificationbased assay like PCR [31-33]. The major problem regarding $\mathrm{HCV}$ testing is most of the diagnostic centres rely on single type of rapid screening test and do not verify the positive test result by highly specific and sensitive serological assays or HCV RNA testing. The reasons behind this may be due to the lack of facilities in laboratories for such testing, lack of understanding the performance and interpretation of the screening and additional $\mathrm{HCV}$ test and finally the high cost of the additional $\mathrm{HCV}$ test [32,33]. Recently $\mathrm{HCV}$ testing in resource-limited settings is major concern worldwide. Most of the people from developing countries are unable to get the facilities of proper diagnosis and management of infectious diseases. Therefore infectious diseases like HIV, HBV and $\mathrm{HCV}$ are increases rapidly throughout the world. Therefore it is mandatory to implicate the standard diagnostic and management strategies against infectious diseases. Therefore in this study we developed a highly specific, sensitive and inexpensive enzyme-linked immunosorbent assay for the rapid detection of $\mathrm{HCV}$ infection. The sensitivity and specificity of in-house HCV ELISA were recorded 96.66 and $100 \%$ respectively as compared to HCV RT PCR result. Out of 60 reactive specimen confirmed by HCV RT PCR, 59 showed reactive by HCV ELISA and 1 specimen showed false negative result. The false negative result may be due to the old storage sample use in assay validation purpose or else the antibody titre in the specimen was not enough to capture in the HCV antigen coated well. While we compared our test result with
HCV chemiluminescence enzyme immune assay, the specificity and sensitivity reported similar for both the method (Table 1). The performance of HCV ELISA in filed was showed better result as compared with HCV chemiluminescence enzyme immune assay. Total of 400 sera tested and sensitivity and specificity was similar to the chemiluminescence method. Several other authors also reported the sensitivity and specificity was similar for $3^{\text {rd }}$ generation HCV ELISA and chemiluminescence method, which is supported our findings [32-34]. Most of the individuals from resource-limited areas; a group of sex workers, homeless or prisoners has a higher risk of $\mathrm{HCV}$ infection than other population. Due to the insufficient facilities or poor acceptability and feasibility of venipuncture $\mathrm{HCV}$ testing in those individuals are limited. Therefore collecting capillary blood spot on filter card is proved to be easiest and cost-effective method in resource-limited areas and high-risk groups $[35,36]$. In this study we developed Genomix Whatman filter card for the collection of blood specimens. We examined the suitability of Dried Blood Spot (DBS) in detecting anti-HCV by using HCV ELISA. The specificity and sensitivity of DBS anti-HCV detection was excellent as per our findings. There was no significant difference on O.D. values obtained by using direct sera and DBS (Figures 1 and 4). Some of the other studies also reported the similar results [37-39]. The detection of $\mathrm{HCV}$ infection by ELISA combined with DBS is appropriate for epidemiological studies and diagnosis in resource-limited areas. The highly specific and sensitive HCV ELISA use as a point of care diagnostic assay, we validated our assay with hand-held ELISA reader. This is the first study which establishes Hand-held ELISA reader use in clinical diagnostic purpose. The Hand-held ELISA reader is easy to use, lightweight and easy to carry the instrument in study field. With the aid of handheld ELISA reader, we can perform ELISA test outside the standard laboratory or in resource-limited areas. In this study hand-held Elisa reader perform excellent as compared to existing ELISA plate reader. There was no significant difference found in O.D. value obtained from both the reader (Figures 2 and 5).

Table 1. In-house HCV ELISA performance $(n=210)$.

\begin{tabular}{|c|c|c|c|c|c|c|}
\hline Method & Reactive & Non-reactive & Sensitivity & Specificity & $\begin{array}{l}\text { Positive predictive } \\
\text { value }\end{array}$ & $\begin{array}{l}\text { Negative predictive } \\
\text { value }\end{array}$ \\
\hline Qiagen HCV RT-PCR & 60 & 150 & $100 \%$ & $100 \%$ & $100 \%$ & $100 \%$ \\
\hline In-house HCV ELISA & 59 & 150 & $98.33 \%$ & $100 \%$ & $100 \%$ & $98.70 \%$ \\
\hline HCV chemiluminescence assay & 59 & 150 & $98.33 \%$ & $100 \%$ & $100 \%$ & $99.33 \%$ \\
\hline
\end{tabular}

Table 2. Performance of HCV ELISA in field $(n=400)$.

\begin{tabular}{|c|c|c|c|c|c|c|}
\hline Method & Reactive & Non-reactive & Sensitivity & Specificity & $\begin{array}{l}\text { Positive } \\
\text { predictive value }\end{array}$ & $\begin{array}{l}\text { Negative } \\
\text { predictive value }\end{array}$ \\
\hline In-house HCV ELISA & 6 & 394 & $100 \%$ & $100 \%$ & $100 \%$ & $100 \%$ \\
\hline HCV chemiluminescence enzyme immune assay & 6 & 394 & $100 \%$ & $100 \%$ & $100 \%$ & $100 \%$ \\
\hline
\end{tabular}




\section{Limitations}

We performed the study with limited number of specimens, which is not enough to establish our diagnostic strategies in laboratory medicine. Further study with large number of samples required to evaluate the HCV ELISA combined with DBS and Hand-held ELISA reader.

\section{Conclusion}

In conclusion, according to our study report, in-house HCV ELISA is highly specific and sensitive for the detection of HCV infection. A further combination with DBS and Handheld ELISA reader makes it possible to use highly specific and sensitive ELISA in limited resource areas or field level study. In this way we can reduce the cost, a requirement of sophisticated instruments to run the assay.

\section{Acknowledgement}

We would like to thankful to Genomix Molecular Diagnostic and Malla Reddy Hospital for their valuable support.

\section{References}

1. Aach RD, Szmuness W, Mosley JW, Hollinger FB, Kahn RA, Stevens CE, Edwards VM, Werch J. Serum alanine aminotransferase of donors in relation to the risk of nonA,non-B hepatitis in recipients: the transfusion-transmitted viruses study. N Engl J Med 1981; 304: 989-994.

2. Purcell RH, Alter HJ, Dienstag JL. Non-A, non-B hepatitis. Yale J Biol Med 1976; 49: 243-250.

3. Hollinger FB, Gitnick GL, Aach RD, Szmuness W, Mosley JW, Stevens CE, Peters RL, Weiner JM, Werch JB, Lander JJ. Non-A, non-B hepatitis transmission in chimpanzees: a project of the transfusion-transmitted viruses study group. Intervirology 1978; 10: 60-68.

4. Alter HJ, Holland PV, Morrow AG, Purcell RH, Feinstone SM, Moritsugu Y. Clinical and serological analysis of transfusion-associated hepatitis. Lancet 1975; 2: 838-841.

5. David RG. Hepatitis C virus: genomes and molecular biology. Horizon Biosci Norfolk UK 2006.

6. Holland PV, Alter H. Non-A, non-B viral hepatitis. Human Pathol 1981; 12: 1114-1122.

7. Tabor E, Gerety RJ, Drucker JA, Seeff LB, Hoofnagle JH, Jackson DR, April M, Barker LF, Pineda-Tamondong G. Transmission of non-A, non-B hepatitis from man to chimpanzee. Lancet 1978; 1: 463-466.

8. Lavanchy D. The global burden of hepatitis C. Liver Int 2009; 29: 74-81.

9. Lavanchy D. Evolving epidemiology of hepatitis $\mathrm{C}$ virus. Clin Microbiol Infect Off Publ Eur Soc Clin Microbiol Infect Dis 2011; 17: 107-115.

10. Hajarizadeh B, Grebely J, Dore GJ. Epidemiology and natural history of HCV infection. Nat Rev Gastroenterol Hepatol 2013; 10: 553-562.

11. Razali K, Thein HH, Bell J, Cooper-Stanbury M, Dolan K, Dore G, George J, Kaldor J, Karvelas M, Li J, Maher L,
McGregor S, Hellard M, Poeder F, Quaine J, Stewart K, Tyrrell H, Weltman M, Westcott O, Wodak A, Law M. Modelling the hepatitis C virus epidemic in Australia. Drug Alcohol Depend 2007; 91: 228-235.

12. Cornberg M, Razavi HA, Alberti A, Bernasconi E, Buti M, Cooper C, Dalgard O. A systematic review of hepatitis C virus epidemiology in Europe, Canada and Israel. Liver Int 2011; 31: 30-60.

13. Williams IT, Bell BP, Kuhnert W, Alter MJ. Incidence and transmission patterns of acute hepatitis $\mathrm{C}$ in the United States, 1982-2006. Arc Int Med 2011; 171: 242-248.

14. World Health Organization. Blood safety. Glob Datab Blood Safety Rep 2011.

15. Hoofnagle JH. Hepatitis C: the clinical spectrum of disease. Hepatology 1997; 26: 15-20.

16. Shakil AO, Contry-Cantilena C, Alter HJ, Hayashi P, Kleiner DE, Tedeschi V, Krawczynski K. Volunteer blood donors with antibody to hepatitis $\mathrm{C}$ vírus: clinical, biochemical, virologic and histologic features. Ann Intern Med 1995; 123: 330-337.

17. World Health Organisation. Hepatitis C (Fact sheet $\left.N^{\circ} 164\right)$ 2015.

18. Kamili S, Drobeniuc J, Araujo AC, Hayden TM. Laboratory diagnostics for hepatitis $\mathrm{C}$ virus infection. Clin Infect Dis 2012; 55: 43-48.

19. Hosseini-Moghaddam SM, Iran-Pour E, Rotstein C, Husain S, Lilly L, Renner E, Mazzulli T. Hepatitis C core Ag and its clinical applicability: potential advantages and disadvantages for diagnosis and follow-up? Rev Med Virol 2012; 22: 156-165.

20. Marin MG, Bresciani S, Puoti M, Rodella A, Gussago A, Ravaggi A, Pizzocolo G, Albertini A, Cariani E. Clinical significance of serum hepatitis $\mathrm{C}$ virus (HCV) RNA as marker of HCV infection. J Clin Microbiol 1994; 32: 3008-3012.

21. Yun ZB, Lindh G, Weiland O, Johansson B, Sonnerborg A. Detection of hepatitis $\mathrm{C}$ virus (HCV) RNA by PCR related to $\mathrm{HCV}$ antibodies in serum and liver histology in Swedish blood donors. J Med Virol 1993; 39: 57-61.

Stephane C, Jean-MP. Hepatitis C virus serologic and virologic tests and clinical diagnosis of $\mathrm{HCV}$ related liver disease. Int J Med Sci 2006; 3: 35-40.

22. Ekta G, Meenu B, Ashish C. Hepatitis C virus: screening, diagnosis and interpretation of laboratory assays. Asian J Transfus Sci 2014; 8: 19-25.

23. Hui-Chun L, Shih-Yen L. Hepatitis C virus: virology, diagnosis and treatment. World J Hepatol 2015; 7: 1377-1389.

24. Girish JK, Bahige MB, Ken Kuramato I, Frances FM. Detection of acute hepatitis $\mathrm{C}$ virus infection by ELISA using a synthetic peptide comprising a structural epitope. Proc Nat Acad Sci 1992; 89: 4486-4489.

25. Roy K, Hay G, Andragetti R, Taylor A, Goldberg D, Wiessing L. Monitoring hepatitis $\mathrm{C}$ virus infection among injecting drug users in the European Union: a review of the literature. Epidemiol Infect 2002; 129: 577-585. 
Development of sensitive, specific, point of care enzyme-linked immunosorbent assay combined with DBS and handheld ELISA reader for the rapid detection of hepatitis $C$ virus in resource-limited settings

26. Samuel M, Doherty P. Association between heroin use, needle sharing and tattoos received in prison with hepatitis $\mathrm{B}$ and $\mathrm{C}$ positivity among street-recruited injecting drug users in New Mexico, USA. Epidemiol Infect 2001; 127: 475-484.

27. Hahn J, Shafer K. Hepatitis C virus seroconversion among Young Injection Drug Users: Relationships and risks. J Infect Dis 2002; 186: 1558-1564.

28. Miller C, Johnston C. Opportunities for prevention: Hepatitis $\mathrm{C}$ prevalence and incidence in a cohort of young infection drug users. Hepatology 2002; 36: 737-742.

29. Neelam M, Suchet S. Current testing strategies for hepatitis $\mathrm{C}$ virus infection in blood donors and the way forward. World J Gastroenterol 2014; 20: 2948-2954.

30. CDC. Guidelines for Laboratory testing and result reporting of Antibody to Hepatitis C Virus. Morbid Mortal Week Rep 2003; 52: 3 .

31. David HS. Hepatitis C diagnostic testing. Hepatitis C 2018.

32. Lok AS, Gunaratnam NT. Diagnosis of hepatitis C. Hepatology 1997; 26: 48-56.

33. Kesli R, Ozdemir M, Kurtoglu MG, Baykan M, Baysal B. Antibody tests based on chemiluminescence and enzyme linked immunosorbent assay methods used in the diagnosis of hepatitis C infections in Turkey. J Int Med Res 2009; 37: 1420-1429.
34. Parker S, Cubbit W. A method for the detection and confirmation of antibodies to hepatitis $\mathrm{C}$ virus in dried blood spots. J Viral Hepatitis 1997; 68: 199-205.

35. Parker S, Cubitt W. Hepatitis C antibodies detection in dried blood spots. J Viral Hepatitis 1999; 6: 453-456.

36. Edouard T, Anne-Marie M, Fadi M. Dried blood spot for hepatitis $\mathrm{C}$ virus serology and molecular testing. Hepatology 2010.

37. McCarron B, Fox R, Wilson K, Cameron S, McMenamin J, McGregor G. Hepatitis $\mathrm{C}$ antibody detection in dried blood spots. J Viral Hepat 1999; 6: 453-456.

38. Nico G, Oumaima S, Stefan Ross R. Dried blood spotspreparing and processing for use in immunoassays and in molecular techniques. J Visual Exp 2015; 97: 52619.

\section{*Correspondence to}

Soumendra NM

Department of Research

Saveetha University

India 